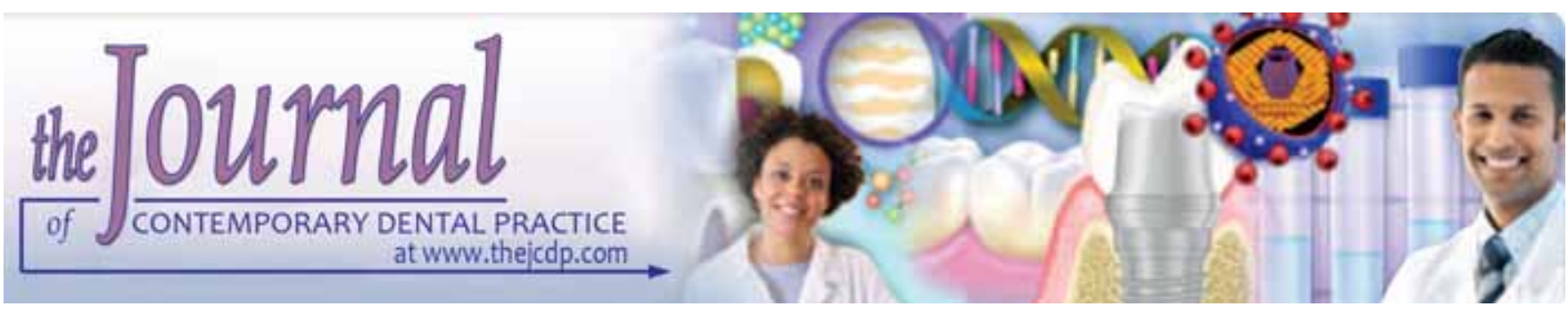

\title{
Can Birth Order Affect Temperament, Anxiety and Behavior in 5 to 7-year-old Children in the Dental Setting?
}

Naser Asl Aminabadi, Azin Sohrabi, Leila Erfanparast, Sina Ghertasi Oskouei, Behjat Almolook Ajami

\section{ABSTRACT}

Aim: The aim of this study was to evaluate the relationships between birth order and child's temperament, anxiety and behavior in the dental setting.

Materials and methods: A total of 200 healthy children aged 5 to 7 years, were included in this double-blind randomized controlled trial. The study consisted of two sessions. In the initial appointment, parents were provided with instructions and asked to complete children's behavior questionnaire (CBQ). In the second appointment, identical dental treatments were rendered to all subjects. During treatment, Frankl scale for child's behavior, facial Image scale (FIS) for situational anxiety, and clinical anxiety rating scale for clinical anxiety were utilized. Analysis of data was done using $U$ Mann-Whitney and Kruskal-Wallis tests.

Results: Only children had higher clinical $(p=0.041)$ and situational $(p<0.001)$ anxiety, and more negative behavior $(p=0.013)$ compared to children with siblings. In children with siblings, first-born child was in increased risk of developing negative behavior $(p=0.008)$, clinical anxiety $(p<0.001)$ and situational anxiety $(p=0.006)$. With an exception (sadness, $p<$ 0.001 ), no significant differences in temperament scale were observed among children with different birth orders.

Conclusion: According to the results, only children and laterborns are at higher risk of developing worse outcomes in the dental setting.

Clinical significance: The role of birth order has been ignored as a possible factor of behavior during routine dental treatment and these findings may shed light on our understanding of behavior management strategies in the dental setting. Considering the increasing pattern of family with an only child both in modern and developing countries, this is more likely that the dental team will face children with negative outcome during dental treatment.

Keywords: Randomized controlled trial, Birth order, Child, Anxiety, Behavior.

How to cite this article: Aminabadi NA, Sohrabi A, Erfanparast L, Oskouei SG, Ajami BA. Can Birth Order Affect Temperament, Anxiety and Behavior in 5 to 7-year-old Children in the Dental Setting? J Contemp Dent Pract 2011;12(4):225-231.

Source of support: Nil

Conflict of interest: None declared

\section{INTRODUCTION}

The evidence demonstrates that the impact of family interaction and caregiving experiences extend beyond traditionally studied psychological outcomes, to neurobiological and physiological outcomes that can impact long-term physical health. ${ }^{1}$ The place of the individual within the family, the first social structure encountered, has been suggested as a contributing factor in shaping human personalities and responses physiological stress. Thus, children's ability to cope with stressors in medical situations may also be determined in part by family interactions and child's age ranking in the family. ${ }^{2}$

Review of the birth order literature suggests a relationship between various indices of cognitive ability, especially verbal ones and facets of emotion knowledge. ${ }^{3}$ Research has shown that there are birth-order differences in intelligence ${ }^{4}$ and in the personality dimensions. ${ }^{5,6}$ Sulloway has proposed a family dynamics model of birthorder effects in personality and behavior. ${ }^{6,7}$ Each archetypical profile, from oldest to youngest, has been assigned certain characteristics that seems consistent with that place in the family system. The first-borns are the center of attention and the sole object of care, ${ }^{8}$ yet the experience of dethronement is thought to make first-borns vulnerable to the effects of stress and uncertain in difficult situations. ${ }^{9}$ With only adults for role models, first-borns take on adult characteristic, such as seriousness, to be in control, organized, on time, goal-oriented, conscientious, responsible, adhere to norms and rules, likes order and structure. ${ }^{10}$ Middle children, on the other hand, can either become the peacemaker or the rebel. ${ }^{11}$ They may exhibit the personality characteristics, including defensiveness, impulsivity, noncompetitive, sociable, sensitive, cooperative, diplomatic, secretive, rebellious and laid- 
back. $^{12}$ Youngest children are believed to be accustomed to receiving attention and thought to misbehave, if they feel a lack of attention. ${ }^{13}$ The only child shares some of the characteristics of the first-born, mainly the high achievement drive, but has their own set of traits. Their world is made up of adults so they relate well to them but may have difficult sharing and cooperating. The only child can display personality traits, including defensiveness, desire novelty, autonomy, perfectionism, confidence, organized, logical and scholarly. ${ }^{6,7,13}$

Despite some inconsistencies, the majority of previous evidence linking birth order and child outcomes reports that middle and youngest children do worse in terms of behavior and anxiety than first-borns, and only children are at increased risk of developing negative behavior and anxiety than children who have siblings in the family. ${ }^{14-22}$ Although the literature provides convincing evidence that child outcomes differ by birth order, to the best of our knowledge, there are no published studies evaluating child outcomes by birth order in the dental setting. Therefore, the aim of the present study was to evaluate the relationships between the children's birth order and their temperament, anxiety, and behavior during dental treatment. We hypothesized that there would be relationships between birth order and the measurements of temperament, behavior and anxiety. The relationships between child's temperament and Frankl scores as well as anxiety score were also evaluated.

\section{MATERIALS AND METHODS}

\section{Study Population}

The participants including 200 healthy children (73 boys and 127 girls) aged 5 to 7 years were enrolled in this doubleblind randomized controlled trial in the Department of Pediatric Dentistry, Tabriz University of Medical Sciences, during the period from January to March 2011. The participants referred to the department of pediatric dentistry for comprehensive assessments as well as routine dental treatments. A comprehensive medical and dental history was taken and a treatment plan established for each patient.

The selected subjects were in complete physical and mental health with no confounding medical history. Following criteria were considered for inclusion in the study:

- No history of posttraumatic stress disorders or specific phobia related to the dental settings

- No history of unpleasant experiences in medical settings

- No previous experience of intraoral injections.

After preliminary selection of 300 subjects who matched the inclusion criteria of the study, a total of 200 random numbers were randomly selected to include in the study.
The study procedure was explained to the parents and an informed written consent was taken. The study procedure was approved by the Research and Ethics Committees of the Tabriz University of Medical Sciences.

\section{Assessment Instruments}

\section{Child's Birth Order}

Parents completed a brief demographic sheet regarding basic information about their child. The demographic questions that were asked included gender, age of their child, the number of children in their family and the birth order position. The participants had to choose from four birth order options being studied, i.e. first-born, middle, youngest and only. This would help in clarifying what ordinal position the subject is in. The middle position was defined as having siblings before and after them no matter how many. If there were four children in the family, child number two and three would both be considered in the middle position.

\section{Child's Behavior}

The child's behavior during treatment was assessed according to Frankl behavior scale. Frankl scale divides observed behavior into four categories, ranging from definitely positive to definitely negative.

Rating 1: Definitely negative. Refusal of treatment, forceful crying, fearfulness or any other overt evidence of extreme negativism.

Rating 2: Negative. Reluctance to accept treatment, uncooperativeness, some evidence of negative attitude but not pronounced (sullen, withdrawn).

Rating 3: Positive. Acceptance of treatment; cautious behavior at times; willingness to comply with the dentist, at times with reservation, but patient follows the dentist's directions cooperatively.

Rating 4: Definitely positive. Good rapport with the dentist, interest in the dental procedures, laughter and enjoyment. ${ }^{23}$ The Kappa value for intraexaminer agreement of data for the Frankl scale was 0.75 .

\section{Child's Anxiety}

For a robust assessment of the child's anxiety, both assessment methods of behavioral and self-report were used.

\section{Clinical Anxiety Rating Scale}

Clinical anxiety rating scale was used as a behavioral assessment scale of anxiety. Since six-point rating scales were used, the scores ranged from 0 to 5 (Table 1 ). ${ }^{24}$ Each judge received several hours of training prior to this study 
to become familiar with the rating scales used. Correlations between judges' ratings in this study ranged from 0.78 to 0.98. In order to avoid bias, the principal investigator who also provided the dental treatment did not serve as a judge.

\section{Child's Situational Anxiety}

The facial image scale (FIS; Fig. 1) was used to assess child's situational anxiety. The FIS comprises a row of five faces ranging from very happy (1) to very unhappy (5). ${ }^{25}$ The children were asked to point at which face they felt most like at that moment. The scale is scored by giving a value ranging from one (the most positive affect face) to five (the most negative affect face).

\section{Children's Behavior Questionnaire: Very Short Form}

The children's behavior questionnaire (CBQ) — very short form ${ }^{26}$-is a measure of temperament for 3 to 7 -year-old children. It was designed as an abbreviated version of the original CBQ. ${ }^{27}$ Through factor analysis of items, the CBQVSF reveals three dimensions of childhood temperament: Surgency, negative affectivity and effortful control. ${ }^{26}$ The very short form CBQ contains 36 items and is intended to be a parent or teacher-rating instrument. The rater responds to each item using a 7-point Likert-type scale with choices ranging from 1 (extremely untrue of your child) to 7 (extremely true of your child). All items are presented in the third person and in statement form (i.e. 'Likes being

\section{Table 1: Clinical anxiety rating scale}

\section{Anxiety rating scale}

0 . Relaxed, smiling, willing and able to converse

1. Uneasy, concerned. During stressful procedure may protest briefly and quietly to indicate discomfort. Hands remain down or partially raised to signal discomfort. Child willing and able to interpret experience as requested. Tense facial expression may have tears in eyes.

2. Child appears scared. Tone of voice, questions and answers reflect anxiety. During stressful procedure, verbal protest, quietly crying, hands tense and raised but not interfering. Child interprets situation with reasonable accuracy and continues to work to cope with anxiety.

3. Shows reluctance to enter situation, difficulty in correctly assessing situational threat. Pronounced verbal protest, crying. Protest out of proportion to threat. Copes with situation with great reluctance.

4. Anxiety interferes with ability to assess situation. General crying not related to treatment. More prominent body movement. Child can be reached through verbal communication and eventually with reluctance and great effort he begins the work of coping with threat.

5. Child out of contact with the reality of the threat. General loud crying, unable to listen to verbal communication, makes no effort to cope with threat, actively involved in escape behavior, physical restraint required.

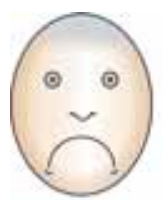

5

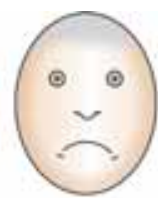

4

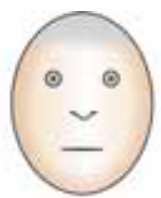

3

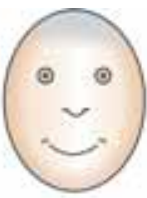

2

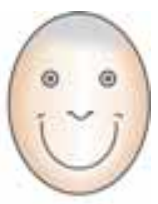

1
Fig. 1: Facial image scale with image scores 1 to 5

sung to', 'Prefers quiet activities to active games' and 'Is good at following instructions'). The very short form CBQ presents high internal consistency for each dimension across samples, ranging from 0.62 to 0.78 , satisfactory criterion validity, stability overtime and agreement across informants (maternal ratings vs paternal ratings). ${ }^{26}$ Therefore, the CBQVSF has acceptable validity and internal consistency. ${ }^{26,28}$

\section{Procedure}

The study consisted of two consecutive sessions. The initial appointment consisted of complimentary dental examination followed by psychological evaluation. Testing was conducted by both of the authors, a trained dental nurse and a psychology postgraduate student.

In the initial appointment, the psychology postgraduate student who carried out psychological evaluations, provided parents with instructions and asked them to complete CBQ.

In the second appointment, a trained postgraduate pediatric student introduced himself to the child. A standardized 'tell, show and do' method was used for all the subjects; each instrument and task was described simply. This operator rendered identical dental treatments to all subjects under study, which included prophylaxis at the beginning of the treatment followed by an amalgam restoration of one of the carious mandibular primary molars without pulp involvement using the inferior alveolar block anesthetic technique and fluoride therapy at the end of the session. During the treatment period, two pediatric dentists who were blind to the results of the CBQ test assessed the child's behavior and anxiety independently during operation. One of the parents was present next to the dental unit during procedures. On a random basis $(n=40)$, a third experimenter along with the two pediatric dentists performed the Frankl and clinical anxiety rating scales to allow for the assessment of interexaminer agreement of data.

\section{Data Analysis}

The baseline characteristics of the study population were compared using the Student t-test, $\chi^{2}$ test or Fisher's exact test as appropriate. The Mann-Whitney $\mathrm{U}$ test was used to compare the anxiety and behavior between the only children and children with siblings. The Kruskal-Wallis test was used to compare variables between first, middle and last-born 
children. The correlation between the facial image scale and clinical anxiety rating scale was determined using the Spearman's correlation coefficient. $\mathrm{p}<0.05$ was considered statistically significant. Data were analyzed using the SPSS software version 13.0 (SPSS Science, Chicago, IL, USA).

\section{RESULTS}

A total of 200 children (73 boys and 127 girls) with the age range of 5 to 7 years (mean age, 6 years 3 months) were enrolled to participate in the trial. Of these children, 107 were only child and 93 had siblings. Also, 25 were firstborn, 50 were middle-born, and 18 were last-born.

Cohen's kappa analyses revealed an excellent interrater agreement for the Frankl and clinical anxiety rating scores.

Our analysis revealed no significant difference in birth order, clinical anxiety, situational anxiety, behavior and temperament between boys and girls ( $p>0.05$ ).

A look at the result in the Table 2 reveals that onlychildren had higher clinical $(\mathrm{p}=0.041)$ and situational $(\mathrm{p}<$ $0.001)$ anxiety and negative behavior $(p=0.013)$ compared to children with siblings (Table 2).

Analysis of the data showed statistically significant differences in behavior of children with siblings. First-born children (2.92 \pm 1.079$)$ compared with middle-born (2.46 $\pm 1.166)$ and last-borns (2.44 \pm 0.984$)$ showed a less negative behavior during dental treatment $(\mathrm{p}=0.008)$.

The results also revealed a significant difference in clinical anxiety between first-born children and the others ( $\mathrm{p}<0.001)$. Mean value for first-born, middle-born and last-born children was $1.50 \pm 1.15,2.11 \pm 1.73$ and $2.81 \pm$ 1.71 respectively.

First-born children also were different in situational anxiety compared with middle and last-born children ( $\mathrm{p}=$ $0.006)$. The mean values of situational anxiety were $2.03 \pm$ $1.58,2.78 \pm 1.35$ and $2.10 \pm 1.26$ for first, middle and lastborn children respectively.

These results imply that higher levels anxiety and negative behavior scores were related to first-born and only children.

\begin{tabular}{|c|c|c|c|}
\hline $\begin{array}{l}\text { Outcome } \\
\text { measures }\end{array}$ & Family size & Mean $\pm S D$ & $p$-value \\
\hline $\begin{array}{l}\text { Clinical anxiety } \\
\text { rating scale }\end{array}$ & $\begin{array}{l}\text { Only children } \\
\text { Children with siblings }\end{array}$ & $\begin{array}{l}2.10 \pm 1.57 \\
2.07 \pm 1.69\end{array}$ & 0.041 \\
\hline $\begin{array}{l}\text { The facial } \\
\text { image scale }\end{array}$ & $\begin{array}{l}\text { Only children } \\
\text { Children with siblings }\end{array}$ & $\begin{array}{l}2.89 \pm 1.44 \\
2.15 \pm 1.41\end{array}$ & $<0.001$ \\
\hline Behavior (Frankl) & $\begin{array}{l}\text { Only children } \\
\text { Children with siblings }\end{array}$ & $\begin{array}{l}1.95 \pm 1.11 \\
2.45 \pm 1.30\end{array}$ & 0.013 \\
\hline
\end{tabular}

With an exception (sadness, $\mathrm{p}<0.001$ ), Kruskal-Wallis test highlighted no significant differences in temperament scale among children with different birth orders. This unexpected result is not confirming our hypothesis.

Spearman's rho correlation analysis revealed a strong positive correlation between clinical and situational anxiety (rho = 0.63, $\mathrm{n}=190, \mathrm{p}<0.001$ ) (Fig. 2).

\section{DISCUSSION}

The study of the impact of a child's rank among siblings in the dental setting has revealed that among the outcome measures there are very noticeable outlier: Middle and youngest children do worse than first-borns on nearly all measures, and only-child subjects are at increased risk of developing anxiety and negative behavior than children who had siblings in the family.

There was a statistically significant correlation between the two anxiety measures comprising the clinical and the situational anxiety scales, during the treatment session. In our view, the result proves the robustness of anxiety measure tools in this study.

In reference to the hypothesis of the study, the findings confirm that the first-borns exhibit less negative behavior than later-born children in the dental setting. This lends support to the vast majority of studies which have shown similar results in first-born children, since they tend to show lower levels of anxiety and better behavioral outcomes than the later-borns. Behrman and Taubman ${ }^{14}$ provided some evidence of a positive effect of being first-born, and Hanushek $^{15}$ found a relationship between the first-born and the best outcomes. Theories that have been put forward to explain this finding include lifespan resource constraints (parents have varying amounts of time and money to provide for their children at different points in their career), parental

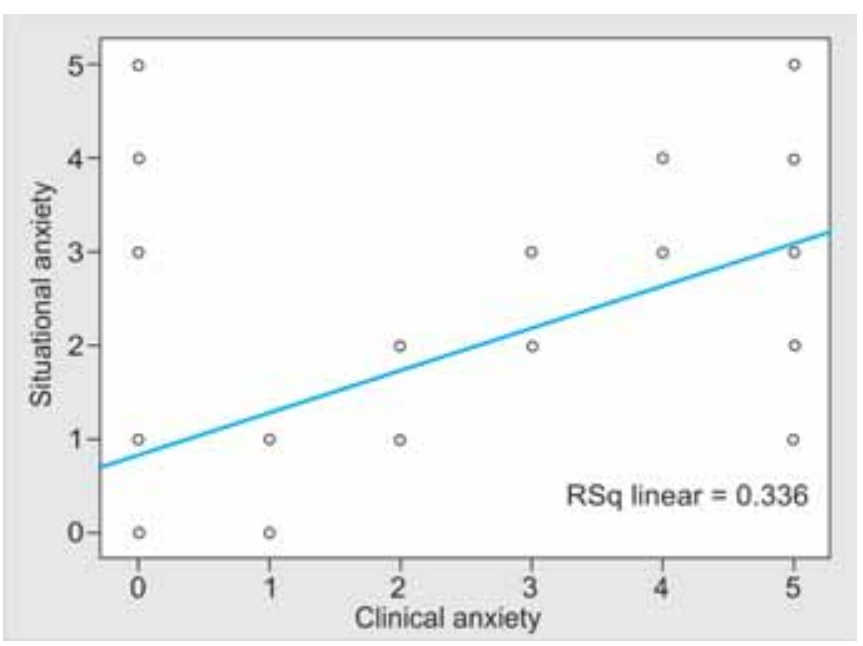

Fig. 2: Scatter plot of correlation between clinical anxiety and situational anxiety 
preferences (parents may enjoy spending more time with the oldest child), optimal stopping models (parents who have a good child are more likely to have more children, such that reversion to the mean increases the likelihood of the second birth being a 'worse' child), biological reserves depletion of parents, different reproductive values of siblings, physiological differences, and the fact that the oldest child gets to be an only child during the early years of his or her life. ${ }^{15}$

Parental time inputs, at a critical early age, are thought to be an important determinant of outcomes. The evidence shows, rather, that parents provide roughly equal time to each of their children at each point in time but spend less time with each child as their children get older. As a result, parents spend more time with the first-born child at each age than they do with the second-born child when he or she reaches the same age. Thus, the parents' apparent desire for equity at each point in time actually leads to inequities in the total resources received by each child (Fig. 3). ${ }^{15}$

Biologically oriented explanations stress the biological reserves depletion of the younger parents, particularly mothers, and argue that as successive children are added to the family, leading to less desirable intrauterine as well as postnatal influences on the development of later-borns. ${ }^{16}$ Another competing hypothesis labeled 'resource dilution' is that parental resources are finite and that siblings are competitors for parents' time, energy and financial resources and, thus, later-born children are competing for a smaller portion of the family reserves. ${ }^{17}$

Some assert that first-borns are more likely to emulate their parents, presumably because the force of their parents' personalities. ${ }^{17}$ Furthermore, oldest children are given responsibility for younger children, which accustoms them

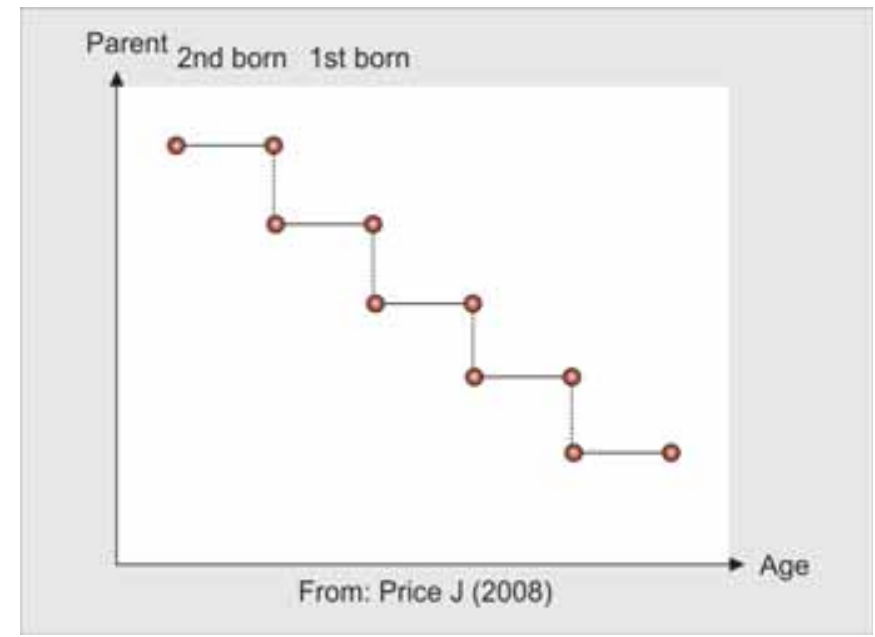

Fig. 3: Parental time inputs. Solid lines represent equity of time received by the first and second-born child at a particular point in time. The dotted lines represent the amount of time the two children receive at the same age early to assuming authority and may give them greater opportunity for self-esteem and self-confidence. ${ }^{16}$

Our study also revealed a significant difference in anxiety between first-borns and later-born children. In accordance with this finding, Howarth found significantly lower anxiety in first-borns as compared to middle and last children and also as compared to single children. ${ }^{18}$ Similar results were found in a clinical sample of children with various forms of psychopathology by Bögels et al, namely that first-born and single children reported less social anxiety than later-born children. ${ }^{19}$

Evidence that negative domination by an older sibling plays a role in the higher anxiety symptoms of younger siblings comes from a study of Dunn et al. Since first-born children show more dominant behavior as a result of hormonal differences as well as age, and children who were dominated in a negative way by their older sibling were more anxious, negative domination may be an important underlying mechanism that explains the higher anxiety in later-born children. Anxiety problems of younger siblings were predicted by a relationship with an older sibling characterized by less intimacy and warmth and by more negative comments from the older sibling. Finally, actual or perceived parental favoritism of the first-born may be a mediator between birth order and anxiety. ${ }^{20}$

We also find that only children are at increased factor of developing anxiety and negative behavior than children who are not alone in the family. Thus, the results are consistent with those reported that the absence of siblings and the higher intimacy with adults could interfere in the intellectual development, in the personality and in the adaptation of the subject to social life. Historically, there have been reports that only children receive excessive attention, mature precociously and, due to the absence of siblings, become selfish, demanding, dependent and moody, in comparison to children with siblings. ${ }^{20}$ Also, in line with our finding, Zimbardo found single children had a greater tendency to be shy than children who were born after siblings. ${ }^{21}$

Two explanations were put forward for this finding. First, it was postulated that parents may set higher expectations for their single children, and as a result, these children may become more sensitive for social failure. Second, because they have a power disadvantage, later-born children may need to acquire social skills more quickly to negotiate personal needs in sibling relationships. ${ }^{22}$ In addition, Zajonc et al stated that children benefit from having a younger sibling to teach, so youngest and 'only' children are disadvantaged by having no younger sibling. ${ }^{4}$ However, some evidences do not confirm the issue about only children, suggesting that they do not present personality problems more frequently than children who have siblings. ${ }^{20}$ 
In this study, the reason for investigating the influence of birth order on temperament was due to its moderating and modulating roles on child behavior and anxiety. Looking at the rest of the data in regards to personality traits, the results of the present study failed to show birth order relationship with personality. Although the findings are somewhat inconsistent, the majority of studies find no significant link between birth order and personality. In line with doubts raised by Ernst and Angst ${ }^{9}$ about the very existence of birth-order effects, several studies have failed to support Sulloway's findings which have proposed a family dynamics model of birth-order effects in personality and behavior. ${ }^{6,7,29-31}$

After examining most of the published research on the topic, Ernst and Angst concluded that 'birth order does not appear to be a very strong influence in molding personality in a definable way'. ${ }^{9}$ Hoffman's investigation of the family environment as a source of differences in sibling personality may offer an explanation for the small magnitude of birthorder effects. She noted that personality outcomes are affected by a multiplicity of interacting environmental influences (including parental intervention, peer relationships and family sibship size) and any single influence is unlikely to explain much variance. ${ }^{32}$ Generally, attempts to link birth order to personality traits have usually shown weak and inconsistent results. ${ }^{30}$ This, however, is contrary to some of the previous works, ${ }^{33-39}$ which indicated statistically significant birth-order-related differences in sibling's personality.

Although these contradictory findings can been explained by differences in study design, methods of data collection, and specific factors evaluated, biological factors may play an important role in child temperament. It has been shown that biological birth-order effects, resulting primarily from intrauterine influences on personality, may in fact account for differences in personality between siblings. Whether it is regarded as primarily psychological, biological, or some combination of the two, birth order seems at least modestly tied to the development of personality. ${ }^{39}$

Birth-order influences are not meant to stereotype people into rigid either-or categories. Such information should be coupled with other issues such as gender, age differences between siblings, socioeconomic families, family atmosphere, family values and culture. ${ }^{34}$

\section{CONCLUSION}

In summary, our results do suggest that only children and later-borns are at higher risk of developing worse outcomes in the dental setting. These results shed new light on a number of aspects of the debate on child's behavioral outcomes during dental treatment. The debate as to whether birth order has an effect on personality development is by no means over, but hopefully with more researchers who are willing to explore new angles and methods in birthorder research, we will better understand the complex interactions between biological, genetic and psychosocial factors.

\section{CLINICAL SIGNIFICANCE}

The role of birth order has been ignored as a possible factor of behavior during routine dental treatment and these findings may shed light on our understanding of behavior management strategies in the dental setting. Considering the increasing pattern of family with an only child in both modern and developing countries, it is more likely that the dental team will face children with negative outcome during dental treatment.

\section{REFERENCES}

1. Luecken LJ, Lemery KS. Early caregiving and physiological stress responses. Clin Psychol Rev 2004;24:171-91.

2. Gould SJ. Dolly's fashion and Louis's passion. Natural History [internet] 1997;106:18-24.

3. Schultz D, Izard CE, Ackerman BP, Youngstrom EA. Emotion knowledge in economically disadvantaged children: Selfregulatory antecedents and relations to social difficulties and withdrawal. Development and Psychopathology 2001;13:53-67.

4. Zajonc RB. The family dynamics of intellectual development. American Psychologist 2001;56:490-96.

5. Paulhus DL, Trapnell PD, Chen D. Birth-order effects on personality and achievement within families. Psychological Science 1999;10:482-88.

6. Sulloway FJ. Born to rebel: Birth-order, family dynamics and creative lives. New York: Pantheon Books 1996.

7. Sulloway FJ. Birth-order, sibling competition, and human behavior. In: Holcomb HR (Ed). Conceptual challenges in evolutionary psychology: Innovative research strategies (3rd ed). Dordrecht, the Netherlands: Kluwer Academic 2001.

8. Richardson RW, Richardson LA. Birth order and you: Discover how your sex and position in the family affects your personality, career, relationships, and parenting (Self-Counsel Personal SelfHelp) (2nd ed). North Vancouver, British Columbia: SelfCounsel Press 2000.

9. Ernst C, Angst J. Birth Order: Its influence on personality (1st ed). New York: Springe 1983.

10. Leman, Kevin. The birth order book : Why you are the way you are? Fleming H Revell, United States of America 1998.

11. Stewart A, Stewart E, Campbell L. The relationship of psychological birth order to the family atmosphere and to personality. J Individual Psychology 2001;57:363-87.

12. Kiedaisch Carol S. The effects of psychological birth order on Golldberg's "Big 5" personality traits. A thesis submitted in partial fulfillment of the requirements of the Masters of School Psychology Degree of the Graduate School at Rowan University. 9 May 2006. 
13. Nims DR. Searching for self: A theoretical model for applying family systems to adolescent group work. J Specialist Group Work 1998;23:133-44.

14. Behrman J, Taubman P. Birth order, schooling and earnings. J Labor Economics 1986;84:121-45.

15. Price J. Parent-child quality time: Does birth order matter? J Human Resources 2008;43:240-65.

16. Draper P, Hames R. Birth order, sibling investment, and fertility among Ju/'Hoansi (! Kung). Human Nature 2000;11:117-56.

17. Downey DB. Number of siblings and intellectual development. The resource dilution explanation. J Am Psychol 2001;56:497-504.

18. Howarth E. Birth order, family structure and personality variables. J Personality Assessment 1980;44:299-301.

19. Bögels SM, Van Oostern A, Muris P, Smulders D. Familial correlates of social anxiety in children and adolescents. Behavior Research and Therapy 2001;39:273-87.

20. Tavaresa MB, Costa Fuchsa F, Diligentia F, Pinto de Abreub JR, Rohdeb LA, Costa Fuchsa S. Behavioral characteristics of the only child $v$ s first-born and children with siblings. Rev Bras Psiquiatr 2004;26:16-22.

21. Bögels SM, Brechman-Toussaint ML. Family issues in child anxiety: Attachment, family functioning, parental rearing and beliefs. Clin Psychol Rev 2006;26:834-56.

22. Susan M, Bögels A, Margaret L, Brechman-Toussaint. Family issues in child anxiety: Attachment, family functioning, parental rearing and beliefs. Clin Psychol Rev 2006;26:834-56.

23. Frankl SN, Shiere FR, Fogels HR. Should the parent remain with the child in the dental operatory? J Dent Child 1962;29: 150-63.

24. Venham LL, Gaulin-Kremer E, Munster E, Bengston-Audia D, Cohan J. Interval rating scales for children' dental anxiety and uncooperative behavior. Pediatr Dent 1980;2:195-202.

25. Buchanan H, Niven N. Validation of a facial image scale to assess child dental anxiety. Int J Paediat Dent 2002;12:47-52.

26. Putnam SP, Gartstein MA, Rothbart MK. Measurement of fine grained aspects of toddler temperament: The early childhood behavior questionnaire. Infant Behavior and Development 2006;29:386-401.

27. Rothbart MK, Ahadi SA, Hershey KL, Fisher P. Investigations of temperament at 3 to 7 years: The children's behavior questionnaire. Child Development 2001;72:1394-408.

28. Capaldi DM, Rothbart MK. Development and validation of an early adolescent temperament measure. J Early Adolescence 1992;12:153-73.

29. Michalski RL, Shackelford TK. An attempted replication of the relationships between birth-order and personality. J Res Personality 2002;36:182-88.

30. Jefferson TJ, Herbst JH, McCrae RR. Associations of birthorder and personality traits: Evidence from self-reports and observer ratings. J Res Personality 1998;32:498-509.

31. Skinner NF. Birth-order effects in dominance: Failure to support Sulloway’s view. Psychol Reports 2003;92:387-88.
32. Hoffman LW. The influence of the family environment on personality: Accounting for sibling differences. Psychol Bulletin 1991;110:187-203.

33. Be'gue L, Roche S. Birth order and youth delinquent behavior testing the differential parental control hypothesis in a French representative sample. Psychology, Crime and Law. March 2005;11:73-85.

34. Eickstein D. Empirical studies indicating significant birth-order related personality differences (Electronic version). The Journal of Individual Psychology 2000;56:481-94.

35. Helms-Erikson H, Router AC. Sibling influences on gender development in middle childhood and adolescence: A longitudinal study (Electronic version). Developmental Psychol 2001;37:115-25.

36. Rodhe PA, Atzwanger K, Butovskaya M, Lampert A, Mysterud I, Sanchez-Andres A, et al. Perceived parental favoritism, closeness to kin, and the rebel of the family: The effects of birth order and sex (Electronic version). Evolution and Human Behavior 2003;24:261-76.

37. Sarolglou V, Fiasse L. Birth order, personality, and religion: A study among young adults from a three-sibling family (Electronic version). Personality and Individual Differences 2003;35:19-29.

38. Saad G, Gill T, Nataraajan R. Are later-borns more innovative and nonconforming consumers than first-borns? A Darwinian perspective (Electronic version). J Business Res 2005;58: 902-09.

39. McGowan H, Beck EA. Qualitative investigation of middle siblings. TCNJ J Student Scholarship 2009;6:1-8.

\section{ABOUT THE AUTHORS}

\section{Naser Asl Aminabadi (Corresponding Author)}

Associate Professor, Department of Pediatric Dentistry, Faculty of Dentistry, Tabriz University of Medical Sciences, Tabriz, Iran, Phone: +984113340310, Fax:+984113346977, e-mail: aslaminabadi@gmail.com

\section{Azin Sohrabi}

Assistant Professor, Department of Pediatric Dentistry, Tabriz University of Medical Sciences, Tabriz, Iran

\section{Leila Erfanparast}

Assistant Professor, Department of Pediatric Dentistry, Tabriz University of Medical Sciences, Tabriz, Iran

\section{Sina Ghertasi Oskouei}

Research Assistant, Faculty of Dentistry, Tabriz University of Medical Sciences, Tabriz, Iran

\section{Behjat Almolook Ajami}

Associate Professor, Department of Pediatric Dentistry, Mashhad University of Medical Sciences, Mashhad, Iran 